\title{
Transforming Growth Factor Alpha Dramatically Enhances Oncogene-Induced Carcinogenesis in Transgenic Mouse Pancreas and Liver
}

\author{
ERIC P. SANDGREN, ${ }^{1 *}$ NOREEN C. LUETTEKE, ${ }^{2}$ TING HU QIU, ${ }^{2}$ RICHARD D. PALMITER, ${ }^{3}$ \\ RALPH L. BRINSTER, ${ }^{1}$ AND DAVID C. LEE $^{2,4}$ \\ Laboratory of Reproductive Physiology, School of Veterinary Medicine, University of Pennsylvania, \\ Philadelphia, Pennsylvania 19104'; Lineberger Comprehensive Cancer Center ${ }^{2}$ and Department of \\ Microbiology and Immunology, ${ }^{4}$ School of Medicine, University of North Carolina at Chapel Hill, \\ Chapel Hill, North Carolina 27599; and Howard Hughes Medical Institute and Department \\ of Biochemistry, University of Washington, Seattle, Washington $98195^{3}$
}

Received 29 July 1992/Returned for modification 21 September 1992/Accepted 13 October 1992

\begin{abstract}
To characterize the effect(s) of transforming growth factor alpha (TGF $\alpha$ ) during multistage carcinogenesis, we examined tumor development in pancreas and liver of transgenic mice that coexpressed TGF $\alpha$ with either viral (simian virus $40 \mathrm{~T}$ antigens [TAg]) or cellular (c-myc) oncogenes. In pancreas, TGF $\alpha$ itself was not oncogenic, but it nevertheless dramatically accelerated growth of tumors induced by either oncogene alone, thereby reducing the host life span up to $60 \%$. Coexpression of TGF $\alpha$ and TAg produced an early synergistic growth response in the entire pancreas together with the more rapid appearance of preneoplastic foci. Coexpression of TGF $\alpha$ and $c-m y c$ also accelerated tumor growth in situ and produced transplantable acinar cell carcinomas whose rate of growth was TGF $\alpha$ dependent. In liver, expression of TGF $\alpha$ alone increased the incidence of hepatic cancer in aged mice. However, coexpression of TGF $\alpha$ with c-myc or TAg markedly reduced tumor latency and accelerated tumor growth. Significantly, expression of the TGF $\alpha$ and myc transgenes in hepatic tumors was induced up to 20 -fold relative to expression in surrounding nonneoplastic liver, suggesting that high-level overexpression of these proteins acts as a major stimulus for tumor development. Finally, in both pancreas and liver, combined expression of TGF $\alpha$ and c-myc produced tumors with a more malignant (less differentiated) appearance than did expression of c-myc alone, consistent with an influence of TGFa upon the morphological character of c-myc-induced tumor progression. These findings demonstrate the importance of TGF $\alpha$ expression during multistage carcinogenesis in vivo and point to a major role for this growth factor as a potent stimulator of tumor growth.
\end{abstract}

The development of cancer is widely viewed as a progression of events during which affected cells gradually escape normal restrictions upon growth and mobility. Specific genetic and epigenetic lesions have now been associated with this process (5). For some of these lesions, including activation of proto-oncogenes and inactivation of tumor suppressor genes, a causal contribution to cancer has been demonstrated $(17,26,52)$. For other lesions, the contribution has not been as clearly defined. An example of the latter is enhanced production by tumor cells of transforming growth factor alpha (TGF $\alpha)$.

TGF $\alpha$ is a member of the epidermal growth factor superfamily of polypeptide mitogens, and it binds to and activates the epidermal growth factor receptor (EGFR) (reviewed in references 9,23 , and 29). TGF $\alpha$ protein and mRNA have been detected in preimplantation embryos (33) and midgestation fetuses (53) as well as in a variety of adult tissues (9, 23). The precise physiological functions of TGF $\alpha$ are presently unknown, but this growth factor has been shown to regulate cellular proliferation, migration, and differentiation in vitro $(9,23)$.

Although TGF $\alpha$ is expressed by a variety of normal tissues, its expression is most prevalent and abundant in both spontaneous and experimental tumors and in transformed cell lines. For example, diffuse TGF $\alpha$ immunoreac-

\footnotetext{
* Corresponding author.
}

tivity was detected in epithelium of 80 of 84 human pancreatic adenocarcinomas (3). Additionally, TGF $\alpha$ is produced by several human pancreatic adenocarcinoma cell lines, and it reportedly can enhance their growth in culture via autocrine or paracrine mechanisms $(20,30,45)$. Similarly, transformed rodent liver epithelial cells overexpress TGF $\alpha(13$, $21,22,24,34)$, and increased levels of TGF $\alpha$ can be detected in the urine of patients diagnosed with hepatocellular carcinoma (54). Other tumors, including squamous, renal, and mammary carcinomas, often express elevated levels of TGF $\alpha$ mRNA (11), as do transformed epithelial cell lines derived from mammary gland $(1,4,49)$, colon (19), prostate (16), and skin (35). These observations have been widely interpreted as suggesting that deregulated expression of TGF $\alpha$ contributes to the development of cancer, and this suggestion has been corroborated by demonstrations that TGF $\alpha$ can induce the transformed phenotype in cultured fibroblasts $(6,36,51)$ and mammary epithelial cells $(28,43)$. However, the extent to which expression of TGF $\alpha$ can directly influence the development of cancer in vivo has not yet been fully determined.

To address these and related issues, we previously created transgenic mice carrying a fusion transgene that combined the enhancer/promoter of mouse metallothionein-I (MT) with the coding sequence of rat TGF $\alpha$ (37). MT-TGF $\alpha$ transgenic mice displayed an increased incidence of mammary cancer in postlactational females and of liver tumors in older mice. Several founder males and all males in one 
TABLE 1. Transgenic mouse lines

\begin{tabular}{|c|c|c|}
\hline Transgene (lineage) $)^{a}$ & Reference & Relevant phenotype \\
\hline & & In pancreas \\
\hline MT-TGF $\alpha(1745-8)$ & 37 & $\begin{array}{l}\text { Moderate to severe pancreatic hyperplasia, fibrosis, and pseudoductular metaplasia. } \\
\text { No tumors. }\end{array}$ \\
\hline EL-TGF $\alpha(2262-5)$ & 37 & $\begin{array}{l}\text { Moderate pancreatic hyperplasia, fibrosis, and pseudoductular metaplasia. No } \\
\text { tumors. }\end{array}$ \\
\hline EL-TAg (264-4) & 31 & $\begin{array}{l}\text { Death between } 16 \text { and } 40 \text { weeks of age due to development of multiple acinar cell } \\
\text { carcinomas. }\end{array}$ \\
\hline EL-myc (1195-3) & 38 & $\begin{array}{l}\text { Death between } 12 \text { and } 30 \text { weeks of age due to development of multiple acinar cell } \\
\text { and mixed acinar-ductal carcinomas. } \\
\text { In liver }\end{array}$ \\
\hline MT-TGF $\alpha(1745-8)$ & 37 & Hepatic adenocarcinoma in 1 of 6 mice examined between 36 and 60 weeks of age. \\
\hline AL-TAg (522-8) & 39 & $\begin{array}{l}\text { Death between } 12 \text { and } 18 \text { weeks of age due to development of multiple solid, } \\
\text { trabecular, and cystic hepatic carcinomas. }\end{array}$ \\
\hline AL-myc (741-3) & 39 & $\begin{array}{l}\text { Well-differentiated hepatocellular adenomas in } 4 \text { of } 6 \text { mice examined between } 62 \text { and } \\
100 \text { weeks of age. }\end{array}$ \\
\hline AL-myc (744-8) & 39 & $\begin{array}{l}\text { Solid to trabecular hepatocellular carcinomas in } 3 \text { of } 6 \text { mice examined between } 70 \\
\text { and } 100 \text { weeks of age. }\end{array}$ \\
\hline
\end{tabular}

${ }^{a}$ Published transgenic mouse lineage nomenclature is as follows: line 1745-8, Tg(Mt-1, Tgfa)Bri149; line 2262-5, Tg(Ela-1, Tgfa)Bril51; line 264-4, Tg(Ela1,SV40E+Ela-1,neo)Bri19; line 1195-3, $\mathrm{Tg}(\mathrm{Ela}-1, \mathrm{Myc})$ Bri159; line 522-8, $\mathrm{Tg}(\mathrm{Alb}-1, \mathrm{SV} 40 \mathrm{E}) \mathrm{Bri82}$; line 741-3, $\mathrm{Tg}(\mathrm{Alb}-1, \mathrm{Myc}) \mathrm{Bri82}$; line 744-8, $\mathrm{Tg}(\mathrm{Alb}-1, \mathrm{Myc})$ Bri83.

MT-TGF $\alpha$ lineage developed hyperplastic nodules or adenomas in the coagulation gland. In pancreas, deregulated expression of TGF $\alpha$ did not induce neoplasia but did produce both marked fibroplasia and foci of redifferentiated acinar cells. In many organs, including liver and the gastrointestinal tract, high-level TGF $\alpha$ expression produced twoto threefold increases in organ size and epithelial cell number without otherwise altering tissue architecture. Similar findings were reported by Jhappan et al. (18) for mice carrying an MT-human TGF $\alpha$ fusion transgene. These studies thus confirmed TGF $\alpha$ 's activity as a potent mitogen in vivo, particularly for epithelial cells, and clearly revealed that the effects of deregulated TGF $\alpha$ production are tissue specific.

In this study, we have exploited this transgenic model to further characterize TGF $\alpha$ 's contribution to the development of cancer by examining its ability to influence oncogene-induced carcinogenesis in pancreas and liver. We report that coexpression of TGF $\alpha$ with either the simian virus $40 \mathrm{~T}$ antigens (TAg) or mouse c-myc dramatically enhances tumor growth in both organs.

\section{MATERIALS AND METHODS}

Transgenic mice. The transgenic mice used in this study have been previously described $(31,37-39)$, and their relevant phenotypes are listed in Table 1 . To generate mice carrying two different transgenes, matings were established between selected lines, and resulting offspring were screened for transgenes by probing dot blots of tail DNA as described previously (7). Mice were maintained in a C57BL/6 $\times$ SJL genetic background. Expression of the MT enhancer/promoter was induced by providing mice with 25 $\mathrm{mM} \mathrm{ZnSO}_{4}$ in drinking water at or before the time of weaning ( 3 to 4 weeks of age).

Tissue transplants. Pieces of pancreatic or hepatic tumors 3 to $5 \mathrm{~mm}^{3}$ in size were removed from transgenic mice, placed into separate petri dishes containing 1 to $2 \mathrm{ml}$ of Dulbecco modified Eagle medium, and minced with sterile iris scissors. Each resulting suspension was drawn into a syringe through an 18-gauge needle, and equal volumes were injected subcutaneously between the scapulae of six 3-week- old syngeneic mice. Three mice from each set were provided with water containing $\mathrm{ZnSO}_{4}$ to induce MT-TGF $\alpha$ expression. Recipient mice were examined twice weekly to determine tumor latency (time from transplant until tumors were first palpable) and tumor size. The latter was estimated by measuring the two largest tumor axes with calipers and using the formula for area of an oval to calculate maximal crosssectional area ( $A=\pi a b$, where $a$ and $b$ are hemiaxes).

Gross and histopathology. Mice were sacrificed when moribund or at defined ages during tumor progression and examined for gross lesions. Pancreas and/or liver were fixed in $10 \%$ neutral buffered formalin, embedded in paraffin, sectioned at $5 \mu \mathrm{m}$, stained with hematoxylin and eosin, and examined to determine histopathological diagnoses (25). The total cross-sectional area of fixed pancreas sections was determined by weighing pieces of uniform-weight graph paper trimmed to fit the outline of each section. Immunohistochemistry was performed as described previously (37), using a rabbit antiserum raised against the cytoplasmic domain of the TGF $\alpha$ precursor (kindly provided by Larry Gentry).

RNA analyses. Quantitative solution hybridization was carried out as previously described $(12,37)$. Values for liver were calculated as molecules per diploid nucleus equivalent because of the variation in nuclear ploidy in that organ. For Northern (RNA) analyses, total RNA $(10 \mu \mathrm{g})$ was electrophoresed through $1 \%$ agarose gels containing formaldehyde and transferred to nitrocellulose, and blots were probed with nick-translated cloned cDNA fragments as previously described (37). Prior to Northern analysis, both the integrity and relative concentrations of RNAs were confirmed by electrophoresis through denaturing agarose-urea gels (14). In situ analysis was performed on paraffin sections as described previously (44), using a $\left[{ }^{35}\right.$ S $]$ UTP-labeled TGF $\alpha$ riboprobe derived from a 1.9-kb EcoRI-SalI restriction fragment of the rat TGF $\alpha$ cDNA (6) in plasmid pGEM-4Z. Prior to hybridization, the riboprobe was partially digested in $0.2 \mathrm{M}$ carbonate buffer ( $\mathrm{pH} \mathrm{10.2)} \mathrm{at} 60^{\circ} \mathrm{C}$ for $30 \mathrm{~min}$. The specificity of hybridization was confirmed in control hybridizations carried out with sense-strand riboprobes. 


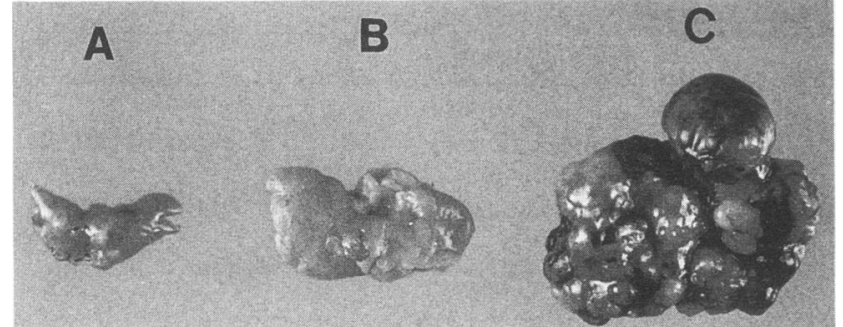

FIG. 1. Gross photograph of mouse pancreases. Each pancreas was removed from a 9-week-old female mouse. The pancreases were from a nontransgenic control (A), a mouse expressing the EL-TAg transgene (B), and a mouse expressing both EL-TGF $\alpha$ (line 2262-5) and EL-TAg (C). See Table 1 for a description of the transgenic lineages used in this cross. Identical results were observed in the cross between MT-TGF $\alpha$ and EL-TAg.

\section{RESULTS}

TGF $\alpha$ and pancreatic carcinogenesis. We previously showed that transgenic mice in which deregulated TGF $\alpha$ expression was targeted to pancreas under the control of either the MT or elastase (EL) enhancer/promoter (37) displayed uniform pancreatic fibrosis and foci of duct-like lesions characterized by redifferentiation of acinar cells. Despite these alterations, only 1 of 31 mice examined at or beyond 36 weeks of age had developed a pancreatic acinar cell carcinoma (the affected mouse was from the highestexpressing EL-TGF $\alpha$ lineage). In this report, we show that although TGF $\alpha$ rarely induces pancreatic tumors alone, its expression dramatically accelerates the development of tumors induced in this organ by either TAg or c-myc.

Figure 1 shows pancreases removed from a 9-week-old nontransgenic mouse (Fig. 1A) and littermates expressing either EL-TAg alone (Fig. 1B) or both EL-TAg and ELTGF $\alpha$ (Fig. 1C). Upon gross examination of these mice, it was immediately apparent that the TGF $\alpha / \mathrm{TAg}$-expressing pancreas was much larger than both normal and TAgexpressing pancreases, largely as the result of the presence of multiple tumor nodules. By comparison, the pancreas expressing TAg alone was only moderately larger than the normal pancreas as a result of oncogene-induced hyperplasia. We further observed that identical morphological changes accompanied coexpression of the MT-TGF $\alpha$ and EL-TAg transgenes. Because MT-regulated TGF $\alpha$ expression is inducible by zinc (37), we chose to use the MT-TGF $\alpha$ lineage mice in all subsequent analyses.

Accelerated tumor development in dual-positive mice coexpressing TGF $\alpha$ and TAg was further reflected by the remarkable finding that all mice bearing both transgenes died before the first TAg single-positive mouse died, and those deaths occurred over a shorter period of time ( 5 versus 20 weeks; Fig. 2A). The average survival of MT-TGF $\alpha \times$ EL-myc transgenic mice was also significantly reduced relative that of mice expressing EL-myc alone (Fig. 2B). Subsequent analysis showed the cause of death in all groups to be the development of multifocal pancreatic tumors.

Tumors present in MT-TGF $\alpha \times$ EL-myc mice frequently were composed of sheets of cells smaller and less differentiated than those found in EL-myc-only tumors (compare Fig. 3A and B). Additionally, most tumors induced by EL-myc alone were mixed acinar-ductal adenocarcinomas, with ductal changes being more abundant in tumors from older mice (38). Ductal elements were not observed in MT-TGF $\alpha \times$ EL-myc tumors, although this observation may simply reflect the reduced life span of these mice. In contrast, we did not observe a major influence of TGF $\alpha$ upon TAg-induced tumor morphology. Finally, TGF $\alpha$ did not obviously influence the vascularity or metastatic potential of either TAg- or c-myc-induced tumors, as determined by gross and histological examination of tumors and other organs (data not shown).

To address the possibility that accelerated pancreatic tumorigenesis resulted from TGF $\alpha$-induced increases in oncogene expression, we compared steady-state levels of TAg and c-myc transcripts in tumors isolated from single- and dual-positive transgenic mice. Although there was a high degree of intertumor variability, quantitative solution hybridization assays revealed no significant differences between expression of $c-m y c$ in TGF $\alpha / c-m y c$ tumors (mean \pm standard error of the mean, $81 \pm 22 ; n=5$ ) versus c-myconly tumors $(113 \pm 51 ; n=2)$, or between expression of TAg in TGF $\alpha / \mathrm{TAg}$ tumors $(56 \pm 16 ; n=11)$ versus TAg-only tumors $(28 \pm 8 ; n=5)$. We also used in situ hybridization analysis to determine that TGF $\alpha$ expression was generally not induced in neoplastic TGF $\alpha / \mathrm{TAg}$ tumor nodules relative
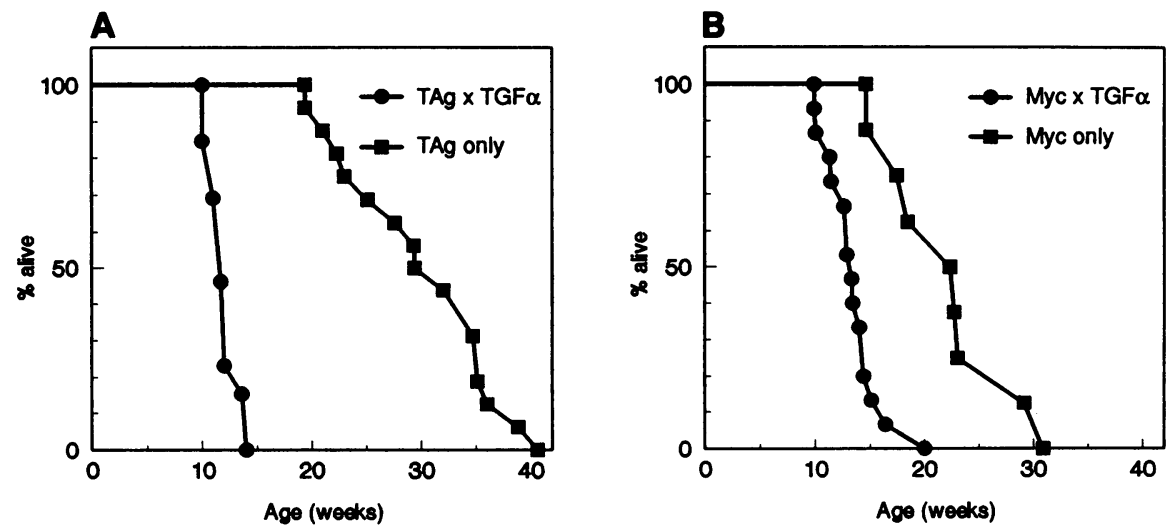

FIG. 2. Survival of mice bearing pancreatic tumors. Percent survival as a function of age is shown in panel A for MT-TGF $\alpha \times$ EL-TAg and EL-TAg transgenic mice and in panel B for MT-TGF $\times$ EL-myc and EL-myc transgenic mice. See Table 1 for a description of the transgenic lineages used in these crosses. (A) $n=13$ for TGF $\alpha \times$ TAg and 16 for TAg only; (B) $n=15$ for TGF $\alpha \times m y c$ and 8 for $m y c$ only. Dual-positive mouse survival is significantly reduced relative to that of the respective single-positive control for each pair at $P<0.00002$, using Student's $t$ test. 

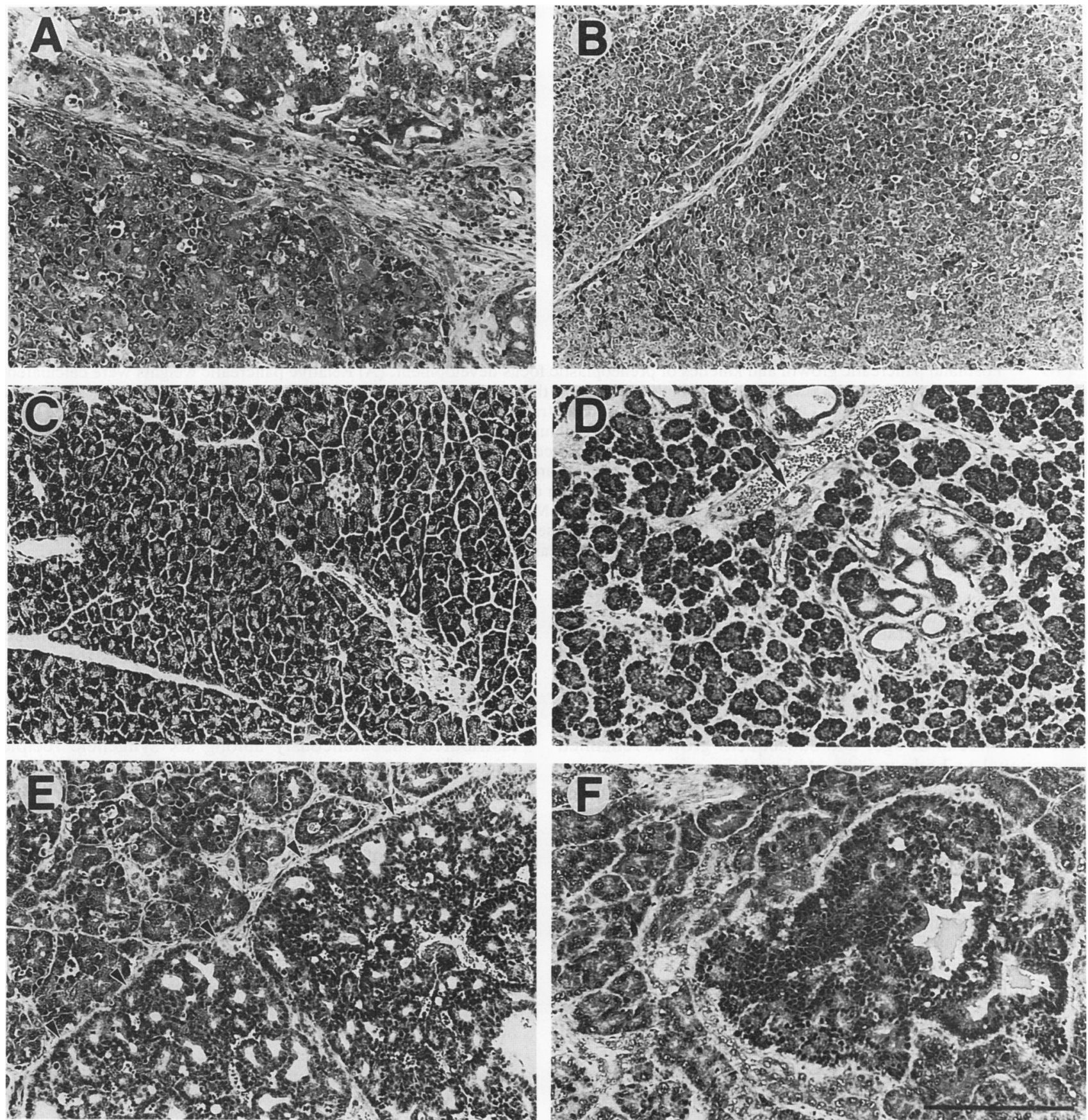

FIG. 3. Histopathology of pancreatic lesions. (A) Poorly differentiated acinar cell carcinoma in a 23-week-old EL-myc transgenic mouse. (B) Solid, undifferentiated acinar cell carcinoma in a 13-week-old MT-TGF $\alpha \times$ EL-myc transgenic mouse. (C) Normal pancreas from a 13-week-old nontransgenic control mouse. (D) Fibrotic pancreas from an 8-week-old MT-TGF $\alpha$ transgenic mouse. Note the separation between most acini, caused by an increase in connective tissue, and the collection of duct-like elements (pseudoducts) to the right of center that result from dilatation and altered differentiation of individual acini (37). A normal pancreatic duct is visible near the center of the photograph (arrow). (E) Pancreas from a 12-week-old EL-TAg transgenic mouse. Dysplastic but nonneoplastic pancreas is present at the upper left. A microcystic atypical acinar cell focus is present at the lower left; its border is indicated by arrowheads. (F) Pancreas from an 8-week-old MT-TGF $\alpha \times$ EL-TAg transgenic mouse. A solid to cystic atypical acinar cell focus is present in the center, causing mild compression of surrounding dysplastic pancreas. The scale bar in panel $\mathrm{F}$ represents $0.2 \mathrm{~mm}$ for all photographs.

to surrounding untransformed pancreas (data not shown). These findings suggest that accelerated pancreatic tumorigenesis is not simply the result of enhanced transgene expression.
We examined pancreases from younger single- and dualpositive mice to identify possible early changes that might accompany or contribute to accelerated tumor formation. Strikingly, a comparison of pancreatic weight as a fraction of 
A

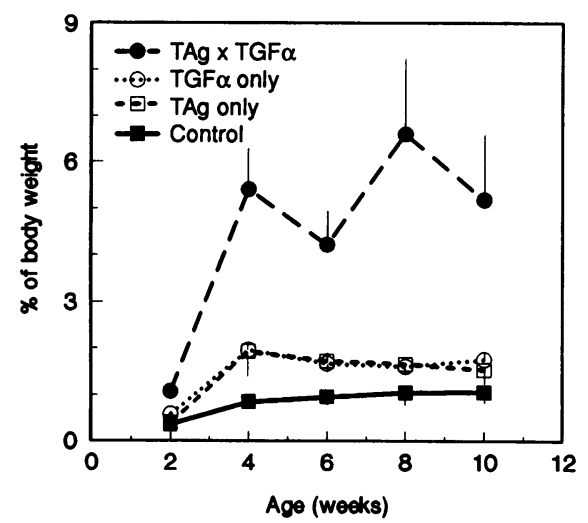

B

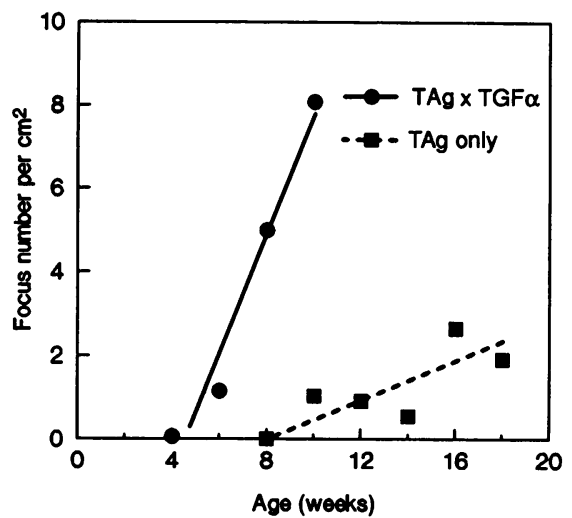

FIG. 4. Postnatal pancreatic growth and kinetics of preneoplastic focus development. (A) Relative pancreatic weights were calculated by expressing pancreatic weight as a fraction of total body weight and then plotted as a function of age for four groups of mice: MT-TGF $\alpha$ EL-TAg mice, MT-TGF $\alpha$ and EL-TAg single-positive mice, and nontransgenic control mice. Each point represents the mean of three to eight measurements (except for 2-week TGF $\alpha$-only, for which $n=2$ ). All mice were administered $\mathrm{ZnSO}_{4}$ in drinking water from conception. Error bars represent standard deviations. All values except those for 2-week TAg-only are significantly different from the corresponding control value at $P<0.05$, using Student's $t$ test. All dual-transgenic values are also significantly different from the corresponding TAg-only value at $P<0.05$. (B) The numbers of preneoplastic foci per square centimeter of pancreatic cross-sectional area in dual- and single-positive transgenic mice carrying the EL-TAg transgene were calculated as described in Materials and Methods and then plotted as a function of age. Each point was determined by examining pancreatic cross sections of four to seven mice. All mice were administered $\mathrm{ZnSO}_{4}$ in drinking water from conception. Distinct preneoplastic foci were not observed in pancreases of single-positive mice carrying only MT-TGF $\alpha$.

total body weight versus age for young mice revealed that whereas expression of either TGF $\alpha$ or TAg alone produced a doubling of relative pancreatic weight, their coexpression synergistically produced a sixfold increase (Fig. 4A). This relative increase in pancreatic weight was essentially complete by 4 weeks of age, and subsequent growth remained proportional to body weight. Although in mice expressing TGF $\alpha$ alone the increase in pancreatic weight was largely the result of fibrosis (compare Fig. 3C and D) (37), MT-TGF $\alpha \times$ EL-TAg pancreases displayed limited fibrosis and, instead, a large increase in the number of dysplastic acinar cells. This alteration is similar to that observed in EL-TAg mice (compare Fig. 3D, E, and F), suggesting that in pancreas, the TAg phenotype is dominant over that of TGF $\alpha$. A comparison of the number of preneoplastic lesions (defined by loss of typical acinar architecture; Fig. 3E and F) per unit crosssectional pancreatic area revealed that lesions were evident at an earlier age in MT-TGF $\alpha \times$ EL-TAg mice than in EL-TAg mice, and the number of these lesions increased more rapidly (Fig. 4B). Note that this analysis was not continued beyond 10 weeks for dual-positive mice or 18 weeks for TAg-only transgenic mice, because after those ages, animals in both groups often displayed one or more large pancreatic tumor nodules that caused an unacceptable data bias. Discrete, unequivocally preneoplastic foci were not evident in EL-myc pancreases; thus, these mice were not similarly analyzed.

The endpoints of the curves shown in Fig. 4B indicate a fourfold increase in the number of foci per unit area detected at a late stage of pancreatic preneoplasia in MT-TGF $\alpha \times$ EL-TAg mice versus EL-TAg single-positive mice. This increase could result from enhanced initiation of foci or the more rapid growth of foci (increasing their chance of being identified and counted). The finding that dual-positive mice began to die as the result of large pancreatic tumors only 4 weeks after the first small pancreatic foci were detected, whereas the first deaths of TAg-only single-positive mice did not occur until 8 weeks after the first foci were detected (compare Fig. 2A and 4B), is consistent with an enhanced growth of foci into tumors. To directly assess the effect of TGF $\alpha$ on tumor growth, several individual primary tumor nodules were removed from MT-TGF $\alpha \times$ EL-myc transgenic mice, and minced suspensions of each nodule were distributed subcutaneously among six syngeneic recipient mice, three of which were induced for MT-TGF $\alpha$ expression. Growth of the resulting transplant nodules was measured twice weekly. As shown for three individual nodules in Fig. 5 and summarized for a larger cohort in Table 2, administration of $\mathrm{ZnSO}_{4}$ in drinking water, which generally augmented expression of TGF $\alpha$ mRNA in subcutaneous nodules without systematically affecting expression of the EL-myc transgene, consistently reduced both tumor latency (the time before a tumor became palpable) and the time required for tumors to reach $100 \mathrm{~mm}^{2}$ in cross-sectional area. In contrast, zinc had no apparent effect on nodules expressing EL-myc alone (Table 2). A similar analysis was carried out with tumors from MT-TGF $\alpha \times$ EL-TAg dual-transgenic mice. In these experiments, neither the latency nor growth rates of subcutaneous tumors were uniformly influenced by $\mathrm{ZnSO}_{4}$ treatment (data not shown). However, we also observed no systematic increase in the level of either MTTGF $\alpha$ or endogenous MT mRNA in these tumors in response to zinc, suggesting that the MT promoter was no longer zinc responsive in end-stage TAg-induced tumors. These results, although not excluding a contribution of TGF $\alpha$ overexpression to enhanced tumor initiation, vividly confirm the ability of induced TGF $\alpha$ expression to stimulate tumor growth in vivo.

TGF $\alpha$ and hepatic carcinogenesis. Although transgenic mice expressing TGF $\alpha$ alone did not show a significantly increased incidence of pancreatic tumors, older transgenic mice did display a higher incidence of hepatic tumors than did nontransgenic controls. Of 27 mice from three MT-TGF $\alpha$ lineages examined between 26 and 104 weeks of age, 16 displayed one or more hepatic tumors up to $2 \mathrm{~cm}$ in diameter. Although most tumors did not appear malignant, three 

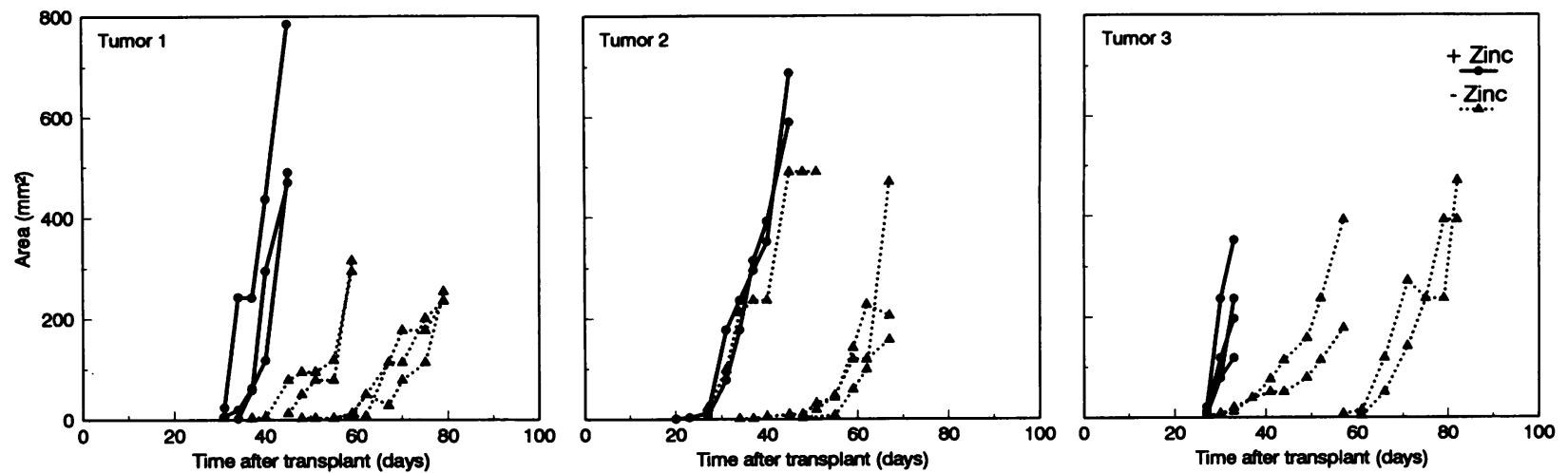

FIG. 5. Growth of transplanted tumor nodules. Maximal cross-sectional area of transplanted tumor nodules is plotted as a function of time after transplant for tissue derived from three different primary tumors. Donor mice carried both the MT-TGF $\alpha$ and EL-myc transgenes. Tissue from each primary tumor was transferred into six syngeneic mice, three of which were administered $\mathrm{ZnSO}_{4}$ in drinking water to induce MT-TGF $\alpha$ expression. On average, tumors appeared earlier and grew more quickly in zinc-induced mice (solid lines). Data from these and three additional transplant experiments are summarized in Table 2.

adenomas contained variably sized foci of carcinoma, two tumors were diagnosed as hepatocellular carcinomas, and one was diagnosed as a cholangiocarcinoma. Nine nodules displayed large, dilated vascular spaces surrounded by narrow sheets of tumor parenchyma (Fig. 6A). In contrast, only 1 of 20 nontransgenic control mice had developed a 5-mmdiameter benign hepatic tumor by 130 weeks of age.

As in pancreas, coexpression of TGF $\alpha$ and c-myc in liver produced a dramatic, synergistic induction of tumors. Two previously established transgenic mouse lines (741-3 and 744-8 [39]) in which c-myc expression was directed to hepatocytes under control of the albumin (AL) enhancer/ promoter each displayed a comparable age-dependent incidence of hepatic lesions (Table 1); two-thirds of these mice developed one to three large tumors beginning at 62 weeks of age. However, when 741-3 lineage AL-myc mice were crossed with MT-TGF $\alpha$ mice and the offspring were induced

TABLE 2. Ratios of growth and transgene expression in EL-myc $\times$ MT-TGF $\alpha$ transplant nodules ${ }^{a}$

\begin{tabular}{lcccc}
\hline & \multicolumn{4}{c}{ Mean \pm SEM $(+\mathrm{Zn} /-\mathrm{Zn})$} \\
\cline { 2 - 5 } Transgene $(n)^{b}$ & $\begin{array}{c}\text { Tumor } \\
\text { latency }\end{array}$ & $\begin{array}{c}\text { Growth to } \\
100 \mathrm{~mm}^{2 c}\end{array}$ & \multicolumn{2}{c}{ mRNA $^{d}$} \\
\cline { 2 - 5 } & & & TGF $\alpha$ & $m y c$ \\
\hline$m y c$ only (2) & $0.93 \pm 0.02$ & $1.01 \pm 0.25$ & & $1.26 \pm 0.06^{e}$ \\
$m y c \times$ TGF $\alpha(6)$ & $0.63 \pm 0.10^{f}$ & $0.52 \pm 0.13^{f}$ & $7.4 \pm 3.2^{f}$ & $0.96 \pm 0.15$ \\
\hline
\end{tabular}

a See Materials and Methods for a description of the procedure. Growth characteristics and transgene expression of transplant nodules isolated from different primary tumors vary greatly. However, nodules derived from MT-TGF $\alpha \times$ EL-myc tumors (though not EL-myc-only tumors) should display zinc-inducible expression of the MT-TGF $\alpha$ transgene. Thus, data are expressed as a ratio of measurements from zinc-induced $(+\mathrm{Zn})$ versus uninduced $(-\mathrm{Zn})$ transplant nodules derived from the same primary tumor, rather than as a ratio of measurements from transplant nodules derived from TGF $\alpha / c-m y c$ versus c-myc-only primary tumors.

${ }^{b}$ myc, EL-myc (Bri159); TGF $\alpha$, MT-TGF $\alpha$ (Bri149). Tumor incidence in each group of recipient mice was $100 \%$. One-millimeter pieces of pancreas from an MT-TGF $\alpha$ mouse were also transplanted into three syngeneic recipients given zinc, but all failed to grow.

$c$ Time in days between first identification of a transplant nodule and its attainment of $100-\mathrm{mm}^{2}$ maximal cross-sectional area.

${ }^{d}$ Determined by quantitative solution hybridization analyses.

e Significantly different from 1 at $P<0.05$, using Student's $t$ test to compare meaningfully paired samples $(+\mathrm{Zn} /-\mathrm{Zn})$.

$f$ Significantly different from 1 at $P<0.025$, using Student's $t$ test to compare meaningfully paired samples $(+\mathrm{Zn} /-\mathrm{Zn})$. for MT-TGF $\alpha$ expression, all dual-positive mice developed up to 10 large, malignant-appearing hepatic tumors and died or were moribund by 38 weeks of age (Fig. 7A). In contrast, and consistent with our previous observations (39), littermates expressing only the c-myc transgene that were sacrificed at the same age displayed no neoplastic hepatic lesions. Hepatic nodules observed in MT-TGF $\alpha \times$ AL-myc transgenic mice included hyperplastic foci (15\%), adenomas (23\%), and solid or trabecular carcinomas (62\%) (Fig. 6B). Most nodules were composed of immature-appearing hepatocytes, and many contained numerous biliary-like cells arranged in nests or streaks. The latter were not conspicuous in tumors induced by c-myc alone, suggesting that TGF $\alpha$ enhanced growth of bile duct epithelium. The malignant character of dual-positive tumors was confirmed by demonstrating their ability to grow rapidly when transplanted into syngeneic hosts (data not shown). This rapid growth of transplanted TGF $\alpha / c-m y c$ hepatic tumors contrasts with previous experiments in which cells from only 1 of 10 transplanted hepatic tumors survived in syngeneic hosts. Tumors previously examined included one from an AL-ras mouse (39), one from an AL-ras $\times$ AL-myc dual-positive mouse, four from AL-urokinase mice (40), and four from AL-TAg mice (39); of these, only one of the latter grew slowly in two of three recipients.

Significantly, all MT-TGF $\alpha \times$ AL-myc tumors greatly overexpressed the transgene relative to normal, surrounding transgenic liver. Quantitative solution hybridization analyses revealed an average 10-fold increase in TGF $\alpha$ transcripts in tumors. Thus, whereas TGF $\alpha$ transcripts were present at a level of $240 \pm 20$ molecules per diploid nucleus equivalent in untransformed liver (mean \pm standard error of the mean; $n=5$ ), the comparable value in tumors was $2,800 \pm 310$ molecules per cell $(n=9)$. For comparison, endogenous MT gene expression increased only twofold $(150 \pm 12[n=4]$ versus $300 \pm 16[n=7])$. This induction of TGF $\alpha$ expression was reflected further by the results of in situ hybridization analyses, which clearly demonstrated elevated levels of TGF $\alpha$ mRNA in tumors compared with adjacent untransformed parenchyma (Fig. 6C). Finally, Northern blot analysis both corroborated the results of in situ and solution hybridization analyses and further demonstrated that the increased levels of TGF $\alpha$ transcripts were the result of enhanced expression of the transgene rather than of the 

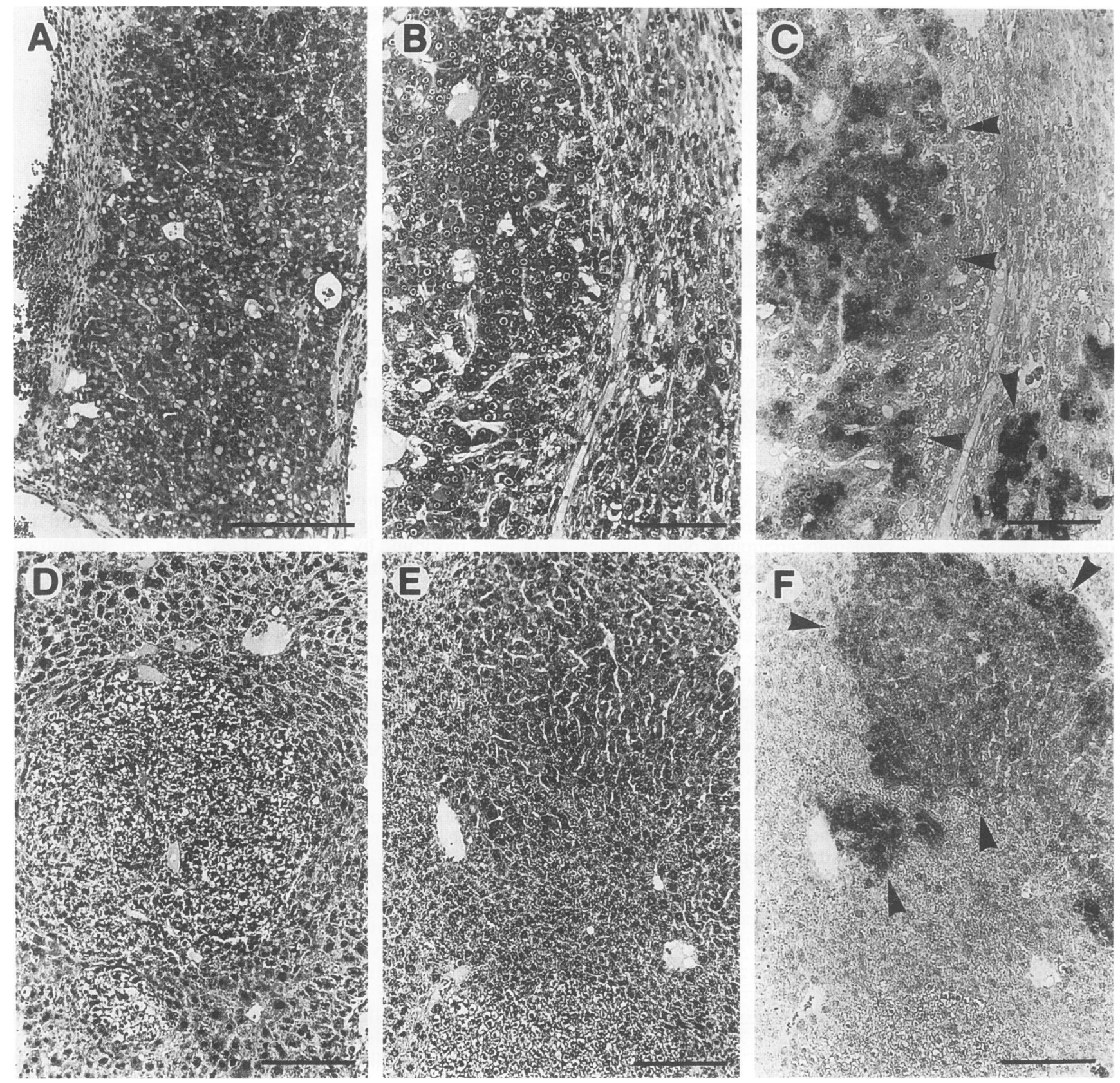

FIG. 6. Histopathology and in situ hybridization analysis of hepatic lesions. (A) Solid to trabecular hepatocellular carcinoma in a 36-week-old MT-TGF $\alpha$ transgenic mouse. Note the large, dilated vascular spaces (some containing erythrocytes) that border the tumor epithelium along three margins. (B) Trabecular hepatocellular carcinoma flanking and compressing nonneoplastic liver (upper right) in a 34-week-old MT-TGF $\alpha \times$ AL-myc transgenic mouse. (C) Section adjacent to that in panel B incubated with an antisense riboprobe complementary to TGF $\alpha$ mRNA. Note the marked increase in the number of silver grains overlying tumor cells (indicated by arrowheads) relative to nonneoplastic hepatocytes. The tumor is also heterogeneous for TGF $\alpha$ expression. (D) A clear cell altered focus (center) in the liver of the mouse represented in panels B and C. Note the dysplastic hepatocytes above and below the focus that display variable nuclear and cytoplasmic size and staining characteristics. (E) A clear cell altered focus (bottom) and a focus of minimally altered cells with slightly dilated sinusoids (top) in the liver of a 30-week-old MT-TGF $\alpha \times$ AL-myc transgenic mouse. (F) Section adjacent to that in (E) incubated with an antisense riboprobe complementary to TGF $\alpha$ mRNA. Note that the minimally altered focus (arrowheads) but not the clear cell focus displays a marked increase in silver grains. The scale bar in each photograph represents $0.2 \mathrm{~mm}$.

endogenous TGF $\alpha$ gene that gives rise to a larger transcript (Fig. 8). Analysis of five independent tumors showed that the increased expression of TGF $\alpha$ transcripts occurred in the absence of increased transgene copy number relative to total tumor DNA content. Hence, three independent assays con- firm that in contrast to pancreas, induced TGF $\alpha$ transgene expression is a frequent event in this model of hepatic carcinogenesis. We note that enhanced transgene expression was not limited to TGF $\alpha$, since most tumors also displayed a moderate to marked elevation in c-myc transgene expres- 

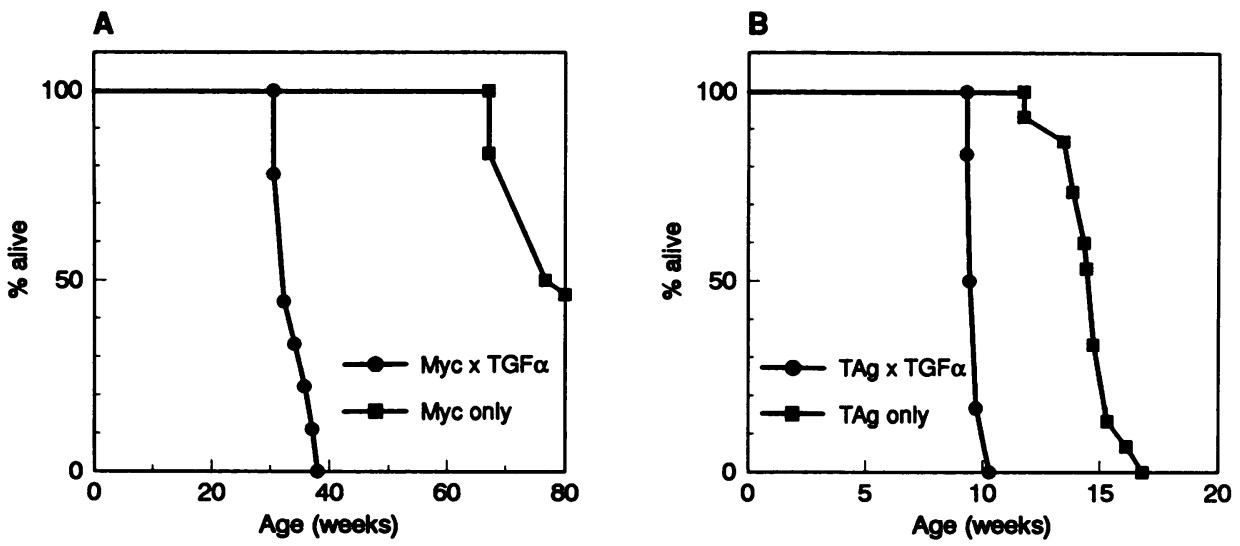

FIG. 7. Survival of mice bearing hepatic tumors. Percent survival as a function of age is shown in panel A for MT-TGF $\times$ AL-myc and AL-myc (line 741-3) transgenic mice and in panel B for MT-TGF $\alpha \times$ AL-TAg and AL-TAg transgenic mice. See Table 1 for a description of the transgenic lineages used in these crosses. (A) $n=9$ for TGF $\alpha \times m y c$ and 6 for $m y c$ only; (B) $n=6$ for TGF $\alpha \times$ TAg and 15 for TAg only. Dual-positive mouse survival is significantly reduced relative to that of the respective single-positive control for each pair at $P<0.00001$, using Student's $t$ test.

sion relative to that in normal surrounding liver (Fig. 8). However, there was no consistent change in the expression of EGFR mRNA in tumors as measured by Northern blot analysis (Fig. 8).

Sections of liver adjacent to tumors in MT-TGF $\alpha \times$ AL-myc mice contained multiple collections of dysplastic hepatocytes that displayed variations in nuclear and cellular size and shape (Fig. 6D). A characteristic type of altered

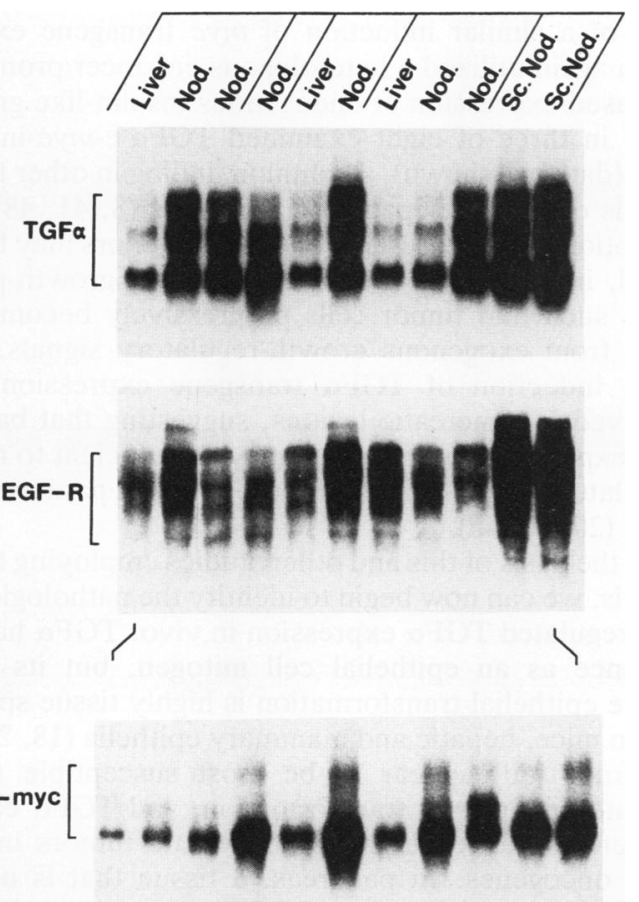

FIG. 8. Northern blot analysis of TGF $/$ /myc-induced hepatic tumors. Blots were probed with a labeled 2.3-kb fragment of the rat TGF $\alpha$ cDNA (top), a 4.0-kb fragment of the rat EGFR cDNA, or a 0.4-kb fragment from exon 2 of the mouse c-myc gene (bottom). Liver (nonneoplastic) and tumor RNAs from the same mouse were placed in adjacent lanes. Nod., nodules; Sc. Nod., transplanted tumor nodules. hepatic focus was also present in almost all sections of nontransformed liver in dual-transgenic mice at the time of sacrifice (Fig. 6D). These foci, which were not observed in either MT-TGF $\alpha$ or AL-myc single-positive mouse livers, consisted of vacuolated cells containing a thin rim of basophilic cytoplasm and generally resembled clear cell foci. When 25 of these foci were examined for the presence of either TGF $\alpha$ protein or TGF $\alpha$ transcripts, only 2 showed elevated expression relative to surrounding normal tissue. Interestingly, a less common class of focus that displayed only minor morphological alterations showed greatly elevated expression of both TGF $\alpha$ protein and transcripts (Fig. $6 \mathrm{E}$ and $\mathrm{F}$ ), suggesting that these may be preneoplastic lesions.

Finally, we also determined that coexpression of TGF $\alpha$ and TAg in liver, as in pancreas, markedly reduced transgenic mouse survival relative to that of mice carrying $\mathrm{TAg}$ alone (Fig. 7B). However, the morphological character of both preneoplastic lesions (altered cell foci of the clear, eosinophilic, and basophilic types) and tumors (adenomas, solid to trabecular carcinomas, and cholangiomas) did not obviously differ between TGF $\alpha / \mathrm{TAg}$ and TAg-only transgenic mice. As in the case of MT-TGF $\alpha \times$ AL-myc tumors, the levels of TGF $\alpha$ transcripts were induced highly in 9 of 12

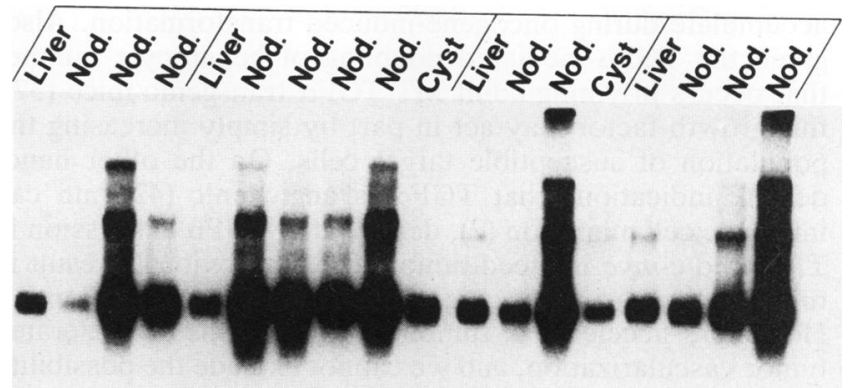

FIG. 9. Northern blot analysis of TGF $\alpha / \mathrm{TAg}$-induced hepatic tumors. Blots were probed with a labeled 2.3-kb fragment of the cloned rat TGF $\alpha$ cDNA. Liver (nonneoplastic) and tumor RNAs from the same mouse were placed in adjacent lanes. The cysts (cholangiomas) did not display elevated MT-TGF $\alpha$ expression. Nod., nodules. 
tumors (though not in cystic cholangiomas) relative to levels in neighboring nonneoplastic liver (Fig. 9), suggesting that transgene induction is a general feature of TGF $\alpha \times$ oncogene-induced hepatocarcinogenesis in the mouse.

\section{DISCUSSION}

In this report, we demonstrate that elevated expression of TGF $\alpha$ under the control of heterologous promoters markedly accelerates oncogene-induced tumorigenesis in two tissues, pancreas and liver. Acting alone in these tissues, TGF $\alpha$ is largely nononcogenic (pancreas) or only moderately oncogenic, inducing tumors with relatively long latency (liver). This finding is consistent with numerous observations that expression of TGF $\alpha$ is elevated in both pancreatic and hepatic cancers as well as in transformed cell lines derived from these tissues $(3,13,20-22,24,30,34,45,54)$. Taken together with our previous finding that deregulated expression of TGF $\dot{\alpha}$ alone induces mammary cancer in nonvirgin female mice with a high incidence (37), these results provide clear confirmation that induced expression of TGF $\alpha$, and perhaps of related growth factors, markedly influences tumor development in vivo. The results further suggest that strategies to interdict TGF $\alpha$-mediated autocrine and paracrine growth loops in human tumors might prolong patient survival.

Our data suggest that a principal consequence of deregulated TGF $\alpha$ expression during oncogene-induced tumorigenesis is the enhancement of tumor growth. Thus, acting in concert with both viral and cellular oncogenes in liver and pancreas, TGF $\alpha$ dramatically stimulated growth of primary tumors in situ as well as of tumors transplanted under the skin of syngeneic hosts. The fact that TGF $\alpha$ alone had only a moderate and generally well-regulated effect upon growth of these organs, as shown in our previous study (37), indicates that a significant step in oncogene-mediated tumor progression is the loss of normal control mechanisms that regulate signal transduction via TGF $\alpha$-activated EGFR and/or the cellular response to that signal. However, several of the present findings suggest that in addition to its obvious enhancement of tumor growth, TGF $\alpha$ may influence other aspects of tumor development, including tumor initiation and phenotype. For example, the marked increase in acinar cell number in the pancreas of TGF $\alpha / \mathrm{TAg}$ mice between 2 and 4 weeks of age occurs just prior to the appearance of preneoplastic foci. Since hyperplasia and tumor promotion are strongly associated in many organs $(10,32)$, the increased cell division in these mice may serve to both create and permanently fix the multiple oncogenic alterations that accumulate during oncogene-induced transformation. Also, given the TGF $\alpha$-mediated doubling of hepatocyte number that occurs in young adult MT-TGF $\alpha$ transgenic mice (37), this growth factor may act in part by simply increasing the population of susceptible target cells. On the other hand, despite indications that TGF $\alpha$ is angiogenic (42) and can influence cell migration (2), deregulated TGF $\alpha$ expression in TAg- and c-myc-induced tumors did not obviously result in tumor hypervascularity or enhanced metastatic potential. However, accelerated tumor growth implies accelerated tumor vascularization, and we cannot exclude the possibility that TGF $\alpha$ accomplishes the former in part by effecting the latter.

Evidence that TGF $\alpha$ can influence tumor phenotype is provided by the observation that TGFa/c-myc-induced tumors in both pancreas and liver generally appeared more malignant than did tumors induced by c-myc alone. This finding is consistent with the previously postulated interaction between TGF $\alpha$ and c-myc during hepatic carcinogenesis. Lee et al. (21), studying a series of 16 clonally derived transformed rat liver epithelial cell lines, found that c-myc expression was positively correlated with tumorigenesis in all clones, but that TGF $\alpha$ expression was highly correlated with tumorigenicity only in those clones that expressed c-myc at levels higher than the median for all clones. Additionally, there have been reports that c-myc overexpression in cultured cells amplifies the effects of autocrine growth circuits, including those involving the EGFR $(46,47)$. Thus, in the context of the additional clonal amplification of TGF $\alpha$ and c-myc transgene expression that we observe in hepatic tumors (see below), deregulated c-myc expression may provide a permissive cellular environment for malignant transformation by TGF $\alpha$, or, conversely, high-level TGF $\alpha$ induction may constitute a rate-limiting step in a c-mycassociated transformation pathway.

A particularly striking result was the observation that expression of the TGF $\alpha$ transgene in dual-positive hepatic lesions was almost always highly induced relative to expression in surrounding tissues. Although the induction mimics the frequently observed deregulation of endogenous TGF $\alpha$ expression in neoplastic cells and tissues, it occurs in the context of a transgene that contains the TGF $\alpha$ coding sequence but that specifically lacks the TGF $\alpha$ enhancer/ promoter elements and 3 ' noncoding sequences that presumably regulate expression of the endogenous gene. The finding that induction of TGF $\alpha$ expression is likely to occur via novel regulatory elements, in this case provided by the MT gene, strongly supports the notion that induction confers a strong selective advantage upon affected cells. Our observations of a similar induction of myc transgene expression, which again utilized a heterologous enhancer/promoter, and increased expression of endogenous insulin-like growth factor II in three of eight examined TGF $\alpha / c-m y c$-induced tumors (data not shown), a common finding in other transgenic models of mouse hepatocarcinogenesis $(8,41,48)$, support the notion that progression of hepatic tumors may be orchestrated, in part, by a global induction of growth-promoting genes such that tumor cells progressively become autonomous from exogenous growth-regulatory signals. Interestingly, induction of TGF $\alpha$ transgene expression was not observed in pancreatic lesions, suggesting that basal transgene expression in this tissue may be sufficient to maximally stimulate TGF $\alpha$-responsive autocrine or paracrine growth loops $(20,30,45)$.

On the basis of this and other studies employing transgenic models, we can now begin to identify the pathological effects of deregulated TGF $\alpha$ expression in vivo. TGF $\alpha$ has a major influence as an epithelial cell mitogen, but its ability to induce epithelial transformation is highly tissue specific $(18$, $37)$. In mice, hepatic and mammary epithelia $(18,27,37)$ and epidermis (50) appear to be most susceptible to TGF $\alpha$ mediated neoplastic transformation, and TGF $\alpha$ can further accelerate the development of hepatic tumors induced by other oncogenes. In pancreas, a tissue that is not readily transformed by elevated TGF $\alpha$ expression, this growth factor still can have a marked influence upon late stages of tumor development by enhancing tumor growth. By conducting studies of this type, we can identify contributions of altered gene expression to multistage carcinogenesis and ultimately apply this knowledge to the design of specific cancer therapy. 


\section{ACKNOWLEDGMENTS}

We thank Diane Allen, Mary Avarbock, and Harmony Kay Phillips for technical assistance, Peter Nowell for helpful discussions, and Glenn Merlino for communicating results prior to publication.

This work was supported by National Institutes of Health grants to R.D.P. (HD-09172), R.L.B. (CA-38635), and D.C.L. (CA-43793) and by American Cancer Society grant BE-91 to D.C.L. N.C.L. was supported by fellowships from the National Cancer Center, Plainview, N.Y., and the National Institutes of Health (GM-14721).

\section{REFERENCES}

1. Ahmed, S. R., B. Badger, C. Wright, and A. Manni. 1991. Role of transforming growth factor- $\alpha$ (TGF $\alpha$ ) in basal and hormonestimulated growth by estradiol, prolactin and progesterone in human and rat mammary tumor cells: studies using TGF- $\alpha$ and EGF receptor antibodies. J. Steroid Biochem. Mol. Biol. 38: $687-693$.

2. Barrandon, Y., and H. Green. 1987. Cell migration is essential for sustained growth of keratinocyte colonies: the roles of transforming growth factor- $\alpha$ and epidermal growth factor. Cell 50:1131-1137.

3. Barton, C. M., P. A. Hall, C. M. Hughes, W. J. Gullick, and N. R. Lemoine. 1991. Transforming growth factor alpha and epidermal growth factor in human pancreatic cancer. J. Pathol. 163:111-116.

4. Bates, S. E., N. E. Davidson, E. M. Valverius, C. E. Freter, R. B. Dickson, J. P. Tam, J. E. Kudlow, M. E. Lippman, and D. S. Salomon. 1988. Expression of transforming growth factor $\alpha$ and its messenger ribonucleic acid in human breast cancer: its regulation by estrogen and its possible functional significance. Mol. Endocrinol. 2:543-555.

5. Bishop, J. M. 1991. Molecular themes in oncogenesis. Cell 64:235-248.

6. Blasband, A. J., D. M. Gilligan, L. F. Winchell, S. T. Wong, N. C. Luetteke, K. T. Rogers, and D. C. Lee. 1990. Expression of the TGF $\alpha$ integral membrane precursor induces transformation of NRK cells. Oncogene 5:1213-1221.

7. Brinster, R. L., H. Y. Chen, M. E. Trumbauer, M. K. Yagle, and R. D. Palmiter. 1985. Factors affecting the efficiency of introducing foreign DNA into mice by microinjecting eggs. Proc. Natl. Acad. Sci. USA 82:4438-4442.

8. Cariani, E., N. Dubois, C. Lasserre, P. Briand, and C. Brechot. 1991. Insulin-like growth factor II (IGF-II) mRNA expression during hepatocarcinogenesis in transgenic mice. J. Hepatol. 13:220-226.

9. Carpenter, G., and M. I. Wahl. 1990. The epidermal growth factor family, p. 69-171. In M. B. Sporn and A. B. Roberts (ed.), Handbook of experimental pharmacology, vol. 95/I. Peptide growth factors and their receptors. Springer-Verlag; Berlin.

10. Cohen, S. M., and L. B. Ellwein. 1990. Cell proliferation in carcinogenesis. Science 249:1007-1011.

11. Derynck, R., D. V. Goeddel, A. Ullrich, J. U. Gutterman, R. D. Williams, T. S. Bringman, and W. H. Berger. 1987. Synthesis of messenger RNAs for transforming growth factors $\alpha$ and $\beta$ and the epidermal growth factor receptor by human tumors. Cancer Res. 47:707-712.

12. Durnam, D. M., and R. D. Palmiter. 1983. A practical approach for quantitating specific mRNAs by solution hybridization. Anal. Biochem. 131:385-393.

13. Grisham, J. W., M.-S. Tsao, D. C. Lee, and H. S. Earp. 1990. Sequential changes in epidermal growth factor receptor/ligand function in cultured rat liver epithelial cells transformed chemically in vitro. Pathobiology 58:3-14.

14. Han, V. K. M., E. S. Hunter, III, R. M. Pratt, J. G. Zendegui, and D. C. Lee. 1987. Expression of rat transforming growth factor alpha mRNA during development occurs predominantly in the maternal decidua. Mol. Cell. Biol. 7:2335-2343.

15. Higashiyama, S., J. A. Abraham, J. Miller, J. C. Fiddes, and M. Klagsbrun. 1991. A heparin-binding growth factor secreted by macrophage-like cells that is related to EGF. Science 251:936939.

16. Hofer, D. R., E. R. Sherwood, W. D. Bromberg, J. Mendelsohn,
C. Lee, and J. M. Kozlowski. 1991. Autonomous growth of androgen-independent human prostatic carcinoma cells: role of transforming growth factor $\alpha$. Cancer Res. 51:2780-2785.

17. Hunter, T. 1991. Cooperation between oncogenes. Cell 64:249270.

18. Jhappan, C., C. Stahle, R. N. Harkins, N. Fausto, G. H. Smith; and G. T. Merlino. 1990. TGF $\alpha$ overexpression in transgenic mice induces liver neoplasia and abnormal development of the mammary gland and pancreas. Cell 61:1137-1146.

19. Karnes, W. E., Jr.; J. H. Walsh, S. V. Wu, R. S. Kim, M. G. Martin, H. C. Wong, J. Mendelsohn, J.-G. Park, and F. Cuttitta. 1992. Autonomous proliferation of colon cancer cells that coexpress transforming growth factor $\alpha$ and its receptor. Gastroenterology 102:474-485.

20. Korc, M., B. Chandrasekar, and G. N. Shah. 1991. Differential binding and biological activities of epidermal growth factor and transforming growth factor $\alpha$ in a human pancreatic cancer cell line. Cancer Res. 51:6243-6249.

21. Lee, L. W., V. W. Raymond, M.-S. Tsao, D. C. Lee, H. S. Earp, and J. W. Grisham. 1991. Clonal cosegregation of tumorigenicity with overexpression of c-myc and transforming growth factor $\alpha$ genes in chemically transformed rat liver epithelial cells. Cancer Res. 51:5238-5244.

22. Liu, C., M.-S. Tsao, and J. W. Grisham. 1988. Transforming growth factors produced by normal and neoplastically transformed rat liver epithelial cells in culture. Cancer Res. 48:850 855.

23. Luetteke, N. C., and D. C. Lee. 1990. Transforming growth factor alpha: expression, regulation and biological action of its integral membrane precursor. Semin. Cancer Biol. 1:265-275.

24. Luetteke, N. C., G. K. Michalopoulos, J. Teixid6, R. Gilmore, J. Massagué, and D. C. Lee. 1988. Characterization of high molecular weight transforming growth factor $\alpha$ produced by rat hepatocellular carcinoma cells. Biochemistry 27:6487-6494.

25. Maronpot, R. R., J. K. Haseman, G. A. Boorman, S. E. Eustis, G. N. Rao, and J. E. Huff. 1987. Liver lesions in B6C3F1 mice: the National Toxicology Program, experience and position. Arch. Toxicol. Suppl. 10:10-26.

26. Marshall, C. J. 1991. Tumor suppressor genes. Cell 64:313-326.

27. Matsui, Y., S. A. Halter, J. T. Holt, B. L. M. Hogan, and R. J. Coffey. 1990. Development of mammary hyperplasia and neoplasia in MMTV-TGF $\alpha$ transgenic mice. Cell 61:1147-1155.

28. McGeady, M. L., S. Kerby, V. Shankar, F. Ciardiello, D. Salomon, and M. Seidman. 1989. Infection with a TGF- $\alpha$ retroviral vector transforms normal mouse mammary epithelial cells but not normal rat fibroblasts. Oncogene 4:1375-1382.

29. Merlino, G. T. 1990 . Epidermal growth factor receptor regulation and function. Semin. Cancer Biol. 1:277-284.

30. Ohmura, E., M. Okada, N. Onoda, Y. Kamiya, H. Murakami, T. Tsushima, and K. Shizume. 1990. Insulin-like growth factor I and transforming growth factor $\alpha$ as autocrine growth factors in human pancreatic cancer cell growth. Cancer Res. 50:103-107.

31. Ornitz, D. M., R. E. Hammer, A. Messing, R. D. Palmiter, and R. L. Brinster. 1987. Pancreatic neoplasia induced by SV40 $\mathrm{T}$-antigen expression in acinar cells of transgenic mice. Science 238:188-193.

32. Pitot, H. C., and Y. P. Dragan. 1991. Facts and theories concerning the mechanisms of carcinogenesis. FASEB J. 5:2280-2286.

33. Rappolee, D. A., C. A. Brenner, R. Schultz, D. Mark, and Z. Werb. 1988. Developmental expression of PDGF, TGF- $\alpha$ and TGF $\beta$ genes in preimplantation mouse embryos. Science 241: 1823-1825.

34. Raymond, V. W., D. C. Lee, J. W. Grisham, and H. S. Earp. 1989. Regulation of transforming growth factor $\alpha$ messenger RNA expression in a chemically transformed rat hepatic epithelial cell line by phorbol ester and hormones. Cancer Res. 49:3608-3612.

35. Reiss, M., E. B. Stash, V. F. Vellucci, and Z.-L. Zhou. 1991. Activation of the autocrine transforming growth factor $\alpha$ pathway in human squamous carcinoma cells. Cancer Res. 51:6254 6262 .

36. Rosenthal, A., P. B. Lindquist, T. S. Bringman, D. V. Goeddel, 
and R. Derynck. 1986. Expression in rat fibroblasts of a human transforming growth factor- $\alpha$ cDNA results in transformation. Cell 46:301-309.

37. Sandgren, E. P., N. C. Luetteke, R. D. Palmiter, R. L. Brinster, and D. C. Lee. 1990. Overexpression of TGF $\alpha$ in transgenic mice: induction of epithelial hyperplasia, pancreatic metaplasia, and carcinoma of the breast. Cell 61:1121-1135.

38. Sandgren, E. P., C. J. Quaife, A. G. Paulovich, R. D. Palmiter, and R. L. Brinster. 1991. Pancreatic tumor pathogenesis reflects the causative genetic lesion. Proc. Natl. Acad. Sci. USA 88:93-97.

39. Sandgren, E. P., C. J. Quaife, C. A. Pinkert, R. D. Palmiter, and R. L. Brinster. 1989. Oncogene-induced liver neoplasia in transgenic mice. Oncogene 4:715-724.

40. Sandgren, E. P., R. D. Palmiter, J. L. Heckel, C. C. Daugherty, R. L. Brinster, and J. L. Degen. 1991. Complete hepatic regeneration after somatic deletion of an albumin-plasminogen activator transgene. Cell 66:245-256.

41. Schirmacher, P., W. A. Held, D. Yang, F. V. Chisari, Y. Rustum, and C. E. Rogler. 1992. Reactivation of insulin-like growth factor-II during hepatocarcinogenesis in transgenic mice suggests a role in malignant growth. Cancer Res. 52:2549-2556.

42. Schreiber, A. B., M. E. Winkler, and R. Derynck. 1986. Transforming growth factor- $\alpha$ : a more potent angiogenic mediator than epidermal growth factor. Science 232:1250-1253.

43. Shankar, V., F. Ciardiello, N. Kim, R. Derynck, D. S. Liscia, G. Merlo, B. C. Langton, D. Sheer, R. Callahan, R. H. Bassin, M. E. Lippman, N. Hynes, and D. S. Salomon. 1989. Transformation of an established mouse mammary epithelial cell line following transfection with a human transforming growth factor alpha cDNA. Mol. Carcinog. 2:1-11.

44. Simmons, D. M., J. L. Arriza, and L. W. Swanson. 1989. A complete protocol for in situ hybridization of messenger RNAs in brain and other tissues with radiolabeled single-stranded RNA probes. J. Histotechnol. 12:169-181.

45. Smith, J. J., R. Derynck, and M. Korc. 1987. Production of transforming growth factor $\alpha$ in human pancreatic cancer cells: evidence for a superagonist autocrine cycle. Proc. Natl. Acad. Sci. USA 84:7567-7570.

46. Sorrentino, V., V. Drozdoff, M. D. McKinney, L. Zeitz, and E. Fleissner. 1986. Potentiation of growth factor activity by exogenous c-myc expression. Proc. Natl. Acad. Sci. USA 83:81678171.

47. Stern, D. F., A. B. Roberts, N. S. Roche, M. B. Sporn, and R. A. Weinberg. 1986. Differential responsiveness of myc- and rastransfected cells to growth factors: selective stimulation of myc-transfected cells by epidermal growth factor. Mol. Cell. Biol. 6:870-877.

48. Takagi, H., R. Sharp, C. Hammermeister, T. Goodrow, M. O. Bradley, N. Fausto, and G. Merlino. 1992. Molecular and genetic analysis of liver oncogenesis in TGF $\alpha$ transgenic mice. Cancer Res. 52:5171-5177.

49. Valverius, E. M., S. E. Bates, M. R. Stampfer, R. Clark, F. McCormick, D. S. Salomon, M. E. Lippman, and R. B. Dickson. 1989. Transforming growth factor $\alpha$ production and epidermal growth factor receptor expression in normal and oncogene transformed human mammary epithelial cells. Mol. Endocrinol. 3:203-214.

50. Vassar, R., and E. Fuchs. 1991. Transgenic mice provide new insights into the role of TGF- $\alpha$ during epidermal development and differentiation. Genes Dev. 5:714-727.

51. Watanabe, S., E. Lazar, and M. B. Sporn. 1987. Transformation of normal rat kidney (NRK) cells by an infectious retrovirus carrying a synthetic rat type $\alpha$ transforming growth factor gene. Proc. Natl. Acad. Sci. USA 84:1258-1262.

52. Weinberg, R. A. 1991. Tumor suppressor genes. Science 254: 1138-1146.

53. Wilcox, J. N., and R. Derynck. 1988. Developmental expression of transforming growth factors alpha and beta in mouse fetus. Mol. Cell. Biol. 8:3415-3422.

54. Yeh, Y. C., J. F. Tsai, L. Y. Chuang, H. W. Yeh, J. H. Tsai, D. L. Florine, and J. P. Tam. 1987. Elevation of transforming growth factor alpha and alpha-fetoprotein levels in patients with hepatocellular carcinoma. Cancer Res. 47:896-901. 